\title{
Genetic polymorphisms in estrogen metabolism and breast cancer risk in case-control studies in Japanese, Japanese Brazilians and non-Japanese Brazilians
}

\author{
Naoki Shimada ${ }^{1}$, Motoki Iwasaki ${ }^{2}$, Yoshio Kasuga ${ }^{3}$, Shiro Yokoyama ${ }^{4}$, Hiroshi Onuma ${ }^{4}$, Hideki Nishimura $^{5}$, \\ Ritsu Kusama ${ }^{6}$, Gerson Shigeaki Hamada ${ }^{7}$, Ines Nobuko Nishimoto ${ }^{8}$, Hirofumi Iyeyasu ${ }^{9}$, Juvenal Motola Jr$^{10}$, \\ Fábio Martins Laginha ${ }^{10}$, Norie Kurahashi ${ }^{2}$ and Shoichiro Tsugane ${ }^{2}$
}

Although many studies have examined associations between single nucleotide polymorphisms (SNPs) in the CYP1A1, CYP1A2 and CYP1B1 genes and breast cancer risk, no study has examined functional SNPs in the CYP3A5 gene and only a small number of studies have been investigated in Japanese populations. To examine the association between six SNPs, CYP1A1*2A,

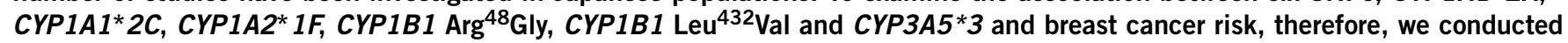
hospital-based case-control studies in Nagano, Japan and São Paulo, Brazil including 873 pairs (403 Japanese (JJ), 81 Japanese Brazilians (JB) and 389 non-Japanese Brazilians (NJB)). Although we found no significant association in the three populations combined, subgroup analyses revealed statistically significant associations of $C Y P 1 A 2 * 1 F$ in $\mathrm{NJB}$, and $C Y P 1 B 1$ $\mathrm{Leu}^{432} \mathrm{Val}$ and $\mathrm{CYP} 3 A 5^{*} 3$ in $\mathrm{JJ}$ with breast cancer risk. Compared to women with the AA genotype in $C Y P 1 A 2 * 1 F$, the odds ratio (OR) $(95 \%$ confidence interval $(\mathrm{CI}))$ for NJB with the CC genotype was $0.54(0.32-0.90)$; that for $\mathrm{JJ}$ with Leu/Val+Val/Val versus Leu/Leu genotype in CYP1B1 Leu ${ }^{432}$ Val was $0.68(0.48-0.97)$; and that for $\mathrm{JJ}$ with $* 3 / * 1+* 1 / * 1$ versus $* 3 / * 3$ genotype in CYP3A5*3 was 1.49 (1.10-2.04). Our findings provide further evidence that genetic polymorphisms related to estrogen metabolism may play a role in the development of breast cancer. Journal of Human Genetics (2009) 54, 209-215; doi:10.1038/jhg.2009.13; published online 20 February 2009

Keywords: breast cancer; case-control study; cytochrome P450; immigrants; single nucleotide polymorphism

\section{INTRODUCTION}

Circulating levels of endogenous estrogens, such as estradiol and estrone have been associated with an increased risk of breast cancer. ${ }^{1}$ An association between circulating levels of estrogen metabolites and risk has also been hypothesized, on the basis that these are potentially both estrogenic and genotoxic. ${ }^{2,3}$ In particular, the association between the urinary ratio of 2-hydroxy (2-OHEs) to 16 $\alpha$-hydroxy estrogens (16 $\alpha$-OHEs) and breast cancer risk has been extensively examined, ${ }^{4-8}$ whereas many studies have also investigated associations between single nucleotide polymorphisms (SNPs) related to estrogen metabolism and risk. ${ }^{2}$

Although many branch pathways in estrogen metabolism have been demonstrated after hydroxylation, the biological properties of the metabolites are determined mainly by the position of the hydroxylation. Estrogen hydroxylation is mediated by cytochrome P450 (CYP) enzymes in the liver, breast tissue or other tissues. Although the sites of localization of metabolism have not been precisely determined, postulated pathways demonstrated in previous expression analyses in human tissues and biochemical experiments are as follows: ${ }^{9,10}$ 2-OHEs formation is likely catalyzed predominantly by CYP1A2 in the liver and CYP1A1 in the breast; 4-hydroxy estrogens (4-OHEs) formation is likely catalyzed predominantly by CYP1A2 in the liver and CYP1B1 in the breast; and 16-OHEs formation is likely catalyzed predominantly by CYP3A5 in the liver and CYP1A1 and CYP3A5 in the breast. Several functional SNPs in these genes have been identified, consisting of variant alleles with higher $\left(C Y P 1 A 1^{\star} 2 A, C Y P 1 A 1^{\star} 2 C\right.$, CYP1B1 $\mathrm{Arg}^{48} \mathrm{Gly}$ and $\left.C Y P 1 B 1 \mathrm{Leu}^{432} \mathrm{Val}\right)^{2}$ or lower or deficient activities $\left(C Y P 1 A 2^{\star} 1 F \text { and } C Y P 3 A 5^{*} 3\right)^{11,12}$ (Table 1). Although a relatively large number of studies have examined associations between these SNPs and the risk of breast cancer, ${ }^{2,13,15,24,25}$ no study has examined the association between functional SNPs in the CYP3A5 gene and the risk of breast cancer, notwithstanding that $C Y P 3 A 5^{\star} 3$

${ }^{1}$ Hokkaido University Graduate School of Medicine, Sapporo, Japan; ${ }^{2}$ Epidemiology and Prevention Division, Research Center for Cancer Prevention and Screening, National Cancer Center, Tokyo, Japan; ${ }^{3}$ Department of Surgery, Nagano Matsushiro General Hospital, Nagano, Japan; ${ }^{4}$ Department of Breast and Thyroid Surgery, Nagano Red Cross Hospital, Nagano, Japan; ${ }^{5}$ Department of Surgery, Nagano Municipal Hospital, Nagano, Japan; ${ }^{6}$ Department of Surgery, Nagano Hokushin General Hospital, Nagano, Japan; ${ }^{7}$ Nikkei Disease Prevention Center, São Paulo, Brazil; ${ }^{8}$ Statistical Section/Head and Neck Surgery and Otorhinolaryngology Department, Hospital A.C. Camargo, São Paulo, Brazil; ${ }^{9}$ Breast Surgery Department, Hospital A.C. Camargo, São Paulo, Brazil and ${ }^{10}$ Department of Breast Surgery, Hospital Pérola Byington, São Paulo, Brazil

Correspondence: Dr M Iwasaki, Epidemiology and Prevention Division, Research Center for Cancer Prevention and Screening, National Cancer Center, 5-1-1 Tsukiji, Chuo-ku, Tokyo, 104-0045, Japan.

E-mail: moiwasak@ncc.go.jp

Received 26 November 2008; revised 16 January 2009; accepted 25 January 2009; published online 20 February 2009 
Table 1 SNPs in genes involved in estrogen metabolism and their properties in previous studies

\begin{tabular}{|c|c|c|c|c|c|c|}
\hline Genes & $d b S N P I D$ & $\begin{array}{l}\text { Polymorphic nucleotide/ } \\
\text { Amino acid change }\end{array}$ & Allele (trivial name) & $\begin{array}{l}\text { Variant } \\
\text { allele }\end{array}$ & Reported variant allele frequency $\%$ a & Presumed variant properties ${ }^{a}$ \\
\hline \multirow[t]{2}{*}{ CYP1A1 } & rs4646903 & T3801C/3'-UTR & $C Y P 1 A 1 * 2 A(\mathrm{~m} 1)$ & $3801 C$ & $\begin{array}{l}\text { Japanese } 36-43 \%,{ }^{13,14} \text { Caucasian } \\
5.2-11.7 \%,{ }^{15} \text { African American } \\
22.9-24.6 \%{ }^{15}\end{array}$ & $\begin{array}{l}\text { increased activity, }{ }^{2} \text { no effect on } \\
\text { urinary ratio of } 2-\mathrm{OHE} 1 / 16 \text { - } \\
\text { OHE } 1^{16}\end{array}$ \\
\hline & rs1048943 & $\mathrm{A} 2455 \mathrm{G} / \mathrm{ll} \mathrm{e}^{462} \mathrm{Val}$ & $C Y P 1 A 1 * 2 C(\mathrm{~m} 2)$ & $462 \mathrm{Val}$ & $\begin{array}{l}\text { Japanese } 25.4 \%,^{13} \text { Caucasian } \\
\text { 3.9-8.6\%,15 African American } \\
0-2.2 \%{ }^{15}\end{array}$ & increased activity and inducibility ${ }^{2}$ \\
\hline \multirow[t]{2}{*}{ CYP1B1 } & rs 10012 & C142G/Arg ${ }^{4}$ Gly & & 48Gly & $\begin{array}{l}\text { Japanese } 9.8 \%,{ }^{18} \\
\text { Caucasian } 28 \%{ }^{19}\end{array}$ & increased activity ${ }^{2}$ \\
\hline & rs 1056836 & G4326C/Leu ${ }^{432} \mathrm{Val}$ & CYP1B $1 * 3$ & $432 \mathrm{Val}^{\mathrm{b}}$ & $\begin{array}{l}\text { Japanese } 20 \%,{ }^{14} \text { Caucasian } \\
43 \%,{ }^{14} \text { African American } 76 \%{ }^{14}\end{array}$ & $\begin{array}{l}\text { three-fold increase in activity }{ }^{2} \text { and } \\
\text { lower urinary ratio of 2-OHE1/16 } \\
\text { a-OHE } 1^{16}\end{array}$ \\
\hline
\end{tabular}

Abbreviations: SNP, single nucleotide polymorphism; UTR, untranslated region.

a Numbers in superscript indicate reference numbers.

bOther studies regard the 433 Leu allele as a variant allele, ${ }^{24}$ but we follow Le Marchand $L$ et al. ${ }^{14}$ in this paper.

causes a splicing defect and decrease in the expression of functional CYP3A5 protein. ${ }^{12}$

Here, to investigate the associations between breast cancer risk and six functional SNPs $\left(C Y P 1 A 1^{\star} 2 A, C Y P 1 A 1^{\star} 2 C, C Y P 1 A 2^{\star} 1 F, C Y P 1 B 1\right.$ $\mathrm{Arg}^{48} \mathrm{Gly}, C Y P 1 B 1 \mathrm{Leu}^{432} \mathrm{Val}$ and $\left.C Y P 3 A 5^{\star} 3\right)$ in genes related to estrogen hydroxylation, we analyzed data from three populations within hospital-based case-control studies in Nagano, Japan and São Paulo, Brazil: Japanese living in Nagano, Japan (JJ), Japanese Brazilians living in São Paulo (JB) and non-Japanese Brazilians living in São Paulo (NJB).

\section{MATERIALS AND METHODS}

\section{Study subjects}

These multicenter, hospital-based case-control studies of breast cancer were designed to determine lifestyle factors and genetic susceptibility to the risk of breast cancer and to compare potential risk factors among JJ, JB and NJB. ${ }^{26}$ Eligible cases were a consecutive series of female patients aged 20-74 years with newly diagnosed and histologically confirmed invasive breast cancer. Cases were recruited between 2001 and 2005 at four hospitals in Nagano, and between 2001 and 2006 at eight hospitals in São Paulo. A total of $405 \mathrm{JJ}$ cases (98\%) participated in Nagano, and 83 JB (91\%) and 389 NJB (99\%) in São Paulo. In the study in Nagano, eligible controls were selected from medical checkup examinees in two of the four hospitals and confirmed not to have cancer. One control was matched for each case by age (within 3 years) and residential area. Among potential controls, one examinee refused to participate and two refused to provide blood samples. Finally, we obtained written informed consent from 405 matched pairs. In the study in São Paulo, eligible controls were preferentially selected from cancer-free patients who visited the same hospital as the index cases. One control was matched for each case by age (within 5 years) and ethnicity. Among potential controls, 22 patients refused to participate (participation rate $=96 \%$ ). Finally, we obtained written informed consent from 472 matched pairs ( 83 for JB and 389 for NJB). The study protocol was approved by CONEP (Comissão Nacional de Ética em Pesquisa), Brasília, Brazil and by the institutional review board of the National Cancer Center, Tokyo, Japan.

Data collection. Participants in Nagano were asked to complete a selfadministered questionnaire, whereas those in São Paulo were interviewed by trained interviewers using a structured questionnaire. The two questionnaires contained closely similar questions concerning demographic characteristics, medical history, family history of cancer, menstrual and reproductive history, anthropometric factors, physical activity and smoking habits. Information on estrogen receptor and progesterone receptor status was obtained from medical records. Hormone receptor status was determined by either enzyme-linked immunoassay or immunohistochemical assay. Hormone receptor positivity values were determined either as specified by the laboratory that performed the assay, or in accordance with the laboratory's written interpretation thereof, or both.

\section{Genotyping}

Genomic DNA samples were extracted from the peripheral blood using QIAGEN FlexiGene DNA Kits according to the manufacturer's protocol. Genotyping of six SNPs, namely CYP1A1 $2 A, C Y P 1 A 1^{\star} 2 C, C Y P 1 A 2^{\star} 1 F$, CYP1B1 $\mathrm{Arg}^{48} \mathrm{Gly}, C Y P 1 B 1 \mathrm{Leu}^{432} \mathrm{Val}$ and $C Y P 3 A 5^{*} 3$, was performed by a commercial laboratory (Genetic Lab. Inc., Sapporo, Japan) using the TaqMan SNP Genotyping Assays developed by Applied Biosystems, USA (Table 1). Cases and matched controls were analyzed in the same well by laboratory personnel who did not know the case-control status.

\section{Statistical analysis}

We excluded subjects whose DNA samples were not available, leaving a total of 873 pairs (403 Japanese (JJ), 81 Japanese Brazilians (JB) and 389 non-Japanese Brazilians (NJB)). Comparison of baseline characteristics between cases and controls was evaluated by the Mantel-Haenszel test using matched-pair strata in each population. Genotype frequencies were tested for deviation from the Hardy-Weinberg equilibrium with the $\chi^{2}$-test. Using a conditional logistic regression model, we calculated odds ratios (ORs) and 95\% confidence intervals (CIs) of breast cancer for SNPs. An unconditional logistic regression model was used for stratified analyses according to menopausal status. In addition to matching factors, the following variables selected mainly based on a comparison of baseline characteristics between cases and controls, were adjusted for as potential confounders: menopausal status (premenopausal women, age at menopause for post-menopausal women $(-43,44-47,48-51$, $52+)$ for the three populations combined, $(-47,48-49,50-51,52+)$ for JJ, $(-47,48-49,50-52,53+)$ for JB, and $(-43,44-47,48-50,51+)$ for NJB), number of births $(0,1,2,3,4+)$ and smoking status (never, ever smokers). All reported $P$-values are two-sided, and significance level was set at $P<0.05$. All 


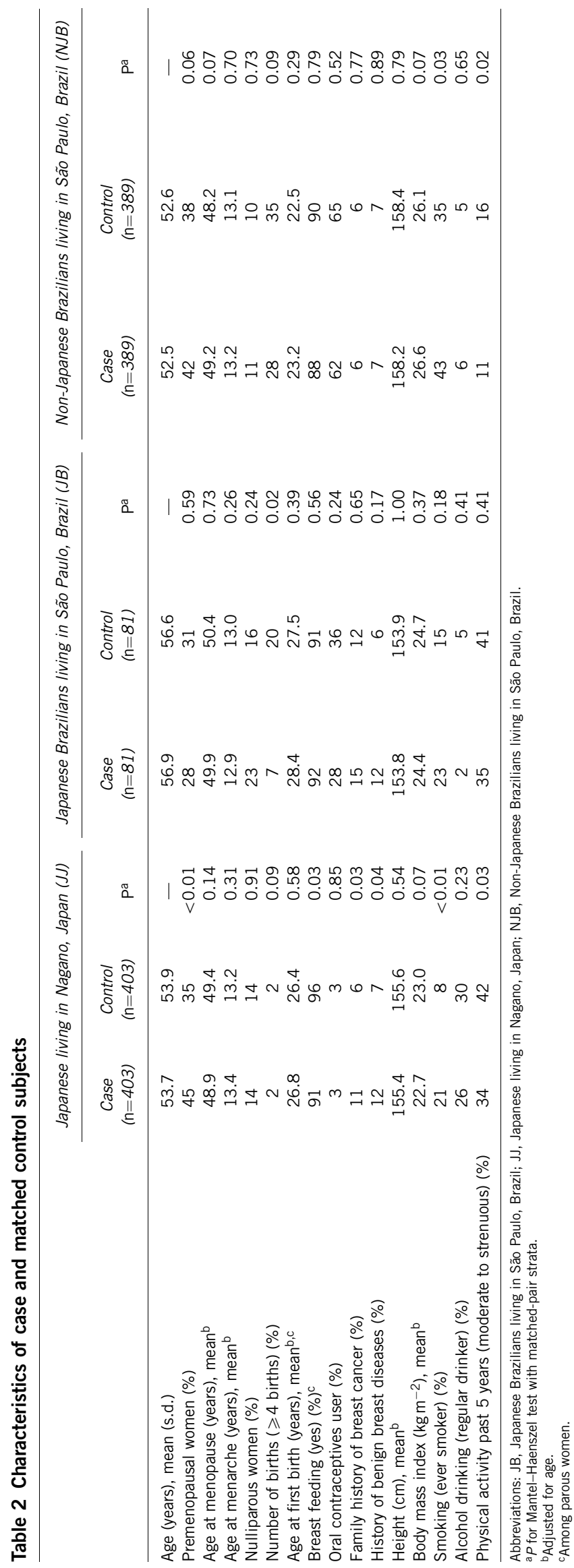

statistical analyses were performed with SAS software version 9.1 (SAS Institute Inc., Cary, NC, USA).

\section{RESULTS}

Characteristics of cases and controls are shown in Table 2. For JJ, cases were more likely to be premenopausal and ever smokers, and tended to have a family history of breast cancer and history of benign breast disease. Cases were less likely than controls to breast feed and be physically active. For JB, cases were less likely than controls to have given birth. For NJB, cases were more likely than controls to be ever smokers and less likely to be physically active.

Allele frequencies of the SNPs among controls in each population are presented in Table 3. Genotype frequencies of each SNP were consistent with the Hardy-Weinberg equilibrium, except for CYP1B1 $\mathrm{Leu}^{432} \mathrm{Val}$ in NJB $(P=0.01)$. The minor allele frequencies of all SNPs were similar between $\mathrm{JJ}$ and JB, and similar allele frequencies of $C Y P 1 A 2^{*} 1 F$ and $C Y P 3 A 5^{*} 3$ were seen among all three populations.

ORs for breast cancer by SNPs are shown in Table 4. We found no statistically significant association between any SNP examined and breast cancer risk in the three populations combined; however, we found a slightly decreased risk of breast cancer among women with the Val allele of CYP1B1 Leu ${ }^{432} \mathrm{Val}$ in comparison with those with the Leu/ Leu genotype. Adjusted ORs (95\% CI) for women with the Leu/Val and Val/Val versus Leu/Leu allele were $0.84(0.67-1.05)$ and 0.82 (0.56-1.19), respectively. No substantial change was seen after further adjustment for other potential confounders, such as age at menarche, age at first birth, body mass index, physical activity in the past 5 years or family history of breast cancer. Further analysis examining the association between the six SNPs and hormone receptor-defined breast cancers showed no remarkable difference in risk by hormone receptor-defined subtype (data not shown).

In the subgroup analyses, we found that three SNPs $\left(C Y P 1 A 2^{*} 1 F\right.$, $C Y P 1 B 1 \mathrm{Leu}^{432} \mathrm{Val}$ and $\left.C Y P 3 A 5^{*} 3\right)$ were significantly associated with breast cancer risk. $C Y P 1 A 2^{*} 1 F$ was significantly associated with risk in NJB but not in the other two populations. Compared to women with the AA genotype in CYP1A2* $1 F$, the adjusted OR (95\% CI) for women with the CC genotype was $0.54(0.32-0.90)$. We found a decreased risk of breast cancer among JJ and JB with at least one Val allele of CYP1B1 Leu $^{432} \mathrm{Val}$ in comparison with those with the Leu/Leu genotype, but not among NJB. The adjusted ORs (95\% CI) for women with the Leu/ $\mathrm{Val}+\mathrm{Val} /$ Val versus Leu/Leu genotype were $0.68(0.48-0.97)$ for JJ and $0.57(0.25-1.30)$ for JB. CYP $3 A 5^{*} 3$ was significantly associated with breast cancer risk in both JJ and JB, but not in NJB. The adjusted OR (95\% CI) for JJ with the ${ }^{\star} 3 /{ }^{\star} 1+{ }^{\star} 1 /{ }^{\star} 1$ versus ${ }^{\star} 3 /{ }^{*} 3$ genotype was 1.49 (1.10-2.04). In contrast, the adjusted OR $(95 \% \mathrm{CI})$ for JB with the ${ }^{\star} 1 /{ }^{*} 1$ versus ${ }^{*} 3 /{ }^{*} 3$ genotype was $0.10(0.02-0.66)$.

Stratified analyses according to menopausal status showed an elevated breast cancer risk among premenopausal but not postmenopausal women with minor alleles in CYP1B1 $\mathrm{Arg}^{48} \mathrm{Gly}$ and $C Y P 3 A 5^{*} 3$ in the three populations combined, although their associations were not statistically significant (data not shown in the Table). The adjusted ORs (95\% CI) for women with the Arg/Gly and Gly/Gly genotypes in CYP1B1 $\mathrm{Arg}^{48}$ Gly were $1.22(0.86-1.73)$ and $1.51(0.78-$ $2.93)$ in premenopausal women, and $1.01(0.76-1.35)$ and $0.99(0.58-$ 1.67 ) in post-menopausal women, respectively, compared with those with the Arg/Arg genotype. The adjusted ORs (95\% CI) for women with the ${ }^{\star} 1 /{ }^{\star} 3$ and ${ }^{\star} 1 /{ }^{\star} 1$ genotypes in $C Y P 3 A 5^{\star} 3$ were $0.94(0.68$ $1.30)$ and $1.53(0.84-2.78)$ in premenopausal women, and $1.14(0.87-$ $1.50)$ and $0.88(0.53-1.44)$ in post-menopausal women, respectively, compared with those with the ${ }^{\star} 3 /{ }^{*} 3$ genotype. This pattern was found predominantly among JJ. Associations between the four other SNPs 
Table 3 Minor allele frequencies of SNPs among control groups

\begin{tabular}{|c|c|c|c|c|}
\hline \multirow{2}{*}{ Genes } & \multirow{2}{*}{ SNP } & \multicolumn{3}{|c|}{ Minor allele frequency (HWE P-value) } \\
\hline & & $J J$ & $J B$ & NJB \\
\hline \multirow[t]{2}{*}{ CYP1A1 } & $C Y P 1 A 1 * 2 A$ & $0.35(0.71)$ & $0.32(0.86)$ & $0.20(0.57)$ \\
\hline & $C Y P 1 A 1 * 2 C$ & $0.22(0.72)$ & $0.21(0.70)$ & $0.10(0.63)$ \\
\hline CYP1A2 & CYP1A2*1F & $0.37(0.93)$ & $0.38(0.81)$ & $0.34(0.08)$ \\
\hline \multirow[t]{2}{*}{ CYP1B1 } & CYP1B1 $\mathrm{Arg}^{48} \mathrm{Gly}$ & $0.12(0.25)$ & $0.10(0.13)$ & $0.34(0.84)$ \\
\hline & CYP1B1 Leu ${ }^{432} \mathrm{Val}$ & $0.15(0.31)$ & $0.16(0.45)$ & $0.44(0.01)$ \\
\hline СУРЗАБ & СУРЗА $5 * 3$ & $0.21^{\mathrm{a}}(0.62)$ & $0.30^{\mathrm{a}}(0.31)$ & $0.27^{\mathrm{a}}(0.15)$ \\
\hline
\end{tabular}

Abbreviations: HWE, Hardy-Weinberg Equilibrium; JB, Japanese Brazilians living in São Paulo, Brazil; JJ, Japanese living in Nagano, Japan; NJB, Non-Japanese Brazilians living in São Paulo, Brazil.

${ }^{\text {aF }}$ or CYP3A5, a minor allele means a wild type allele (CYP $\left.3 A 5^{*} 1\right)$.

and breast cancer risk did not substantially differ by menopausal status.

\section{DISCUSSION}

In these case-control studies, we found no statistically significant association between any of the six SNPs examined and breast cancer risk among the three populations combined. On subgroup analysis, however, statistically significant associations with the risk of breast cancer were seen between $C Y P 1 A 2^{*} 1 F$ in NJB, and $C Y P 1 B 1 \mathrm{Leu}^{432} \mathrm{Val}$ and $C Y P 3 A 5^{*} 3$ in JJ. These findings suggest that genetic polymorphisms related to estrogen metabolism were associated with breast cancer risk, notwithstanding that no overall consistent findings in the three populations were obtained.

The two genetic polymorphisms of CYP1A1 most frequently studied for their association with breast cancer risk are $C Y P 1 A 1^{\star} 2 A$ and $C Y P 1 A 1^{\star} 2 C .^{13-15,27-29}$ A recent meta-analysis showed no overall association between these two SNPs and the risk of breast cancer, ${ }^{15}$ which is in general agreement with our findings. However, a subgroup analysis in this meta-analysis showed that the Val/Val genotype of $C Y P 1 A 1^{\star} 2 C$ was associated with a decreased risk of breast cancer in east Asian women, ${ }^{15}$ which supports the proposed mechanism that women with at least one Val allele may be expected to have higher concentrations of intrinsic 2-OHE1/2 than those with the wild type and to have a decreased risk of breast cancer. However, our present results showed no significant association between $C Y P 1 A 1^{\star} 2 C$ and breast cancer risk.

CYP1A2 is considered as one of the most important enzymes in the 2-hydroxylation of estrogens, ${ }^{3}$ and accumulating evidence indicates an association between $C Y P 1 A 2^{*} 1 F$ and breast cancer risk. ${ }^{14,30-33}$ Findings have been inconsistent, however, showing no association for Chinese, ${ }^{30}$ Caucasian $^{31}$ or American-African women; ${ }^{31}$ a positive association for Russian women; ${ }^{33}$ and an inverse association for a multiethnic group (Multiethnic Cohort Study). ${ }^{14}$ In the present study, we found a significantly decreased risk among NJB with the CC genotype of $C Y P 1 A 2^{\star} 1 F$. Given suggestions that $C Y P 1 A 2^{\star} 1 F$ has two opposite effects on the development of breast cancer, ${ }^{17}$ a growthpromoting effect due to the lower urinary ratio of 2-OHE1/16 $\alpha$-OHE1 and a growth inhibitory effect due to lower levels of serum E2, the decreased risk might reflect a mechanism which involves estrogen level rather than estrogen metabolites.

The remarkable enhancement of enzymatic activity in Val allele carriers has led to a relatively large number of investigations of the association between CYP1B1 Leu ${ }^{432} \mathrm{Val}$ and breast cancer risk. ${ }^{2,24}$ A recent meta-analysis demonstrated that Val allele carriers have a lower risk of breast cancer than Leu/Leu carriers among women of mixed/African ethnicity, but that there is no difference in Asians. ${ }^{24}$ In the present study, Val allele carriers tended to have a decreased risk in the three populations combined and a significantly decreased risk among JJ. These results are inconsistent with those reported for Asians in the meta-analysis. ${ }^{24}$ Previous studies have demonstrated that the Val allele contributes to an increase in 4-hydroxylation activity and a lower urinary 2-OHEs/16 $\alpha$-OHEs ratio (Table 1 ), whereas the Leu allele contributes to an increase in procarcinogen activation. ${ }^{2,16,34}$ Our results might be explained by the latter mechanism. On the other hand, we found no overall association between CYP1B1 $\mathrm{Arg}^{48}$ Gly and breast cancer risk in the three populations combined, which was in good accordance with the majority of previous studies. ${ }^{19,35,36}$

To our knowledge, this is the first epidemiological study to investigate the association between a functional SNP in the CYP3A5 gene and the risk of breast cancer. Although no significant association was found between $C Y P 3 A 5^{\star} 3$ and breast cancer risk among the three populations combined, subgroup analysis revealed a significantly increased risk of breast cancer in JJ women with the $C Y P 3 A 5^{*} 1$ genotype compared with those with the CYP $3 A 5^{*} 3^{*} / 3$ genotype. CYP3A5 may be considered one of the most important CYP enzymes for $16 \alpha$-hydroxylation in vivo. ${ }^{37-39} C Y P 3 A 5^{*} 3$, a nonfunctional allele in CYP3A5, produces a cryptic splicing site leading to the inclusion of a novel exon and ultimately a premature stop codon. In contrast, CYP $3 A 5^{\star} 1$ creates no aberrant CYP3A5 mRNA splicing and is considered a functional allele. ${ }^{12}$ Thus, $C Y P 3 A 5^{\star} 1$ carriers might be expected to have higher endogenous $16 \alpha$-OHEs and higher breast cancer risk. Our finding among JJ supports this hypothesis. Stratified analyses according to menopausal status showed higher risk in premenopausal than post-menopausal women with the ${ }^{\star} 1 /{ }^{\star} 1$ allele, in particular among JJ, and consequently suggest that this SNP may play a more important role in the development of breast cancer in premenopausal than post-menopausal women. In contrast, a decreased risk of breast cancer was observed in $C Y P 3 A 5^{*} 1{ }^{*} 1$ carriers in both JB and NJB. The reason for this inconsistency is unclear, particularly for that between $\mathrm{JJ}$ and JB considering their common genetic background. Given the relatively small number of cases in JB, our findings in this population might merely be due to chance. Alternatively, the decreased risk might be partly explained by enhanced clearance activity of potential oncogenic substances, on the basis that CYP3A activity accounts for the majority of total body clearance for many drugs. ${ }^{40,41}$ CYP3A5 also catalyzes the $6 \beta$-hydroxylation of testosterone, leading to the inactivation of testosterone. For this reason, $C Y P 3 A 5^{*} 1$ is considered a protective genotype of prostate cancer, and an association between $C Y P 3 A 5^{\star} 3$ and prostate cancer risk has been demonstrated. ${ }^{42}$ Therefore, a second possibility is that a portion of endogenous estradiol derived from testosterone might be modulated by the $C Y P 3 A 5^{*} 1$ genotype to result in a lower breast cancer risk among CYP $3 A 5^{\star} 1$ carriers in JB and NJB. Further studies are required to confirm whether the $C Y P 3 A 5^{\star} 3$ mutation is associated with an increased or decreased risk of breast cancer.

Our study has a methodological advantage over previous studies of SNPs related to estrogen metabolism and the risk of breast cancer in that the substantially high participation rates among both eligible cases and controls minimized potential biases related to control selection. Although the use of controls from medical checkup examinees and cancer-free patients, whose lifestyles may have differed from the general population due to health consciousness or disease, might have lead to selection bias, it is less likely that allele frequencies among controls from medical checkup examinees and cancer-free patients differ from those of the general population. In this regard, allele 
Table 4 Odds ratio and $95 \%$ confidence intervals for breast cancer categorized by genetic polymorphism

\begin{tabular}{|c|c|c|c|c|c|c|c|c|c|c|c|c|c|c|c|c|}
\hline \multirow{3}{*}{$\begin{array}{l}\text { Study population - } \\
\text { Genotype }\end{array}$} & \multicolumn{4}{|c|}{ Three populations combined } & \multicolumn{4}{|c|}{$\begin{array}{c}\text { Japanese living in Nagano, } \\
\text { Japan (JJ) }\end{array}$} & \multicolumn{4}{|c|}{$\begin{array}{l}\text { Japanese Brazilians living in } \\
\text { São Paulo, Brazil (JB) }\end{array}$} & \multicolumn{4}{|c|}{$\begin{array}{l}\text { Non-Japanese Brazilians living in } \\
\text { São Paulo, Brazil (NJB) }\end{array}$} \\
\hline & \multicolumn{2}{|c|}{ No. } & \multirow[b]{2}{*}{$O R^{\mathrm{a}}$} & \multirow[b]{2}{*}{$95 \% \mathrm{Cl}$} & \multicolumn{2}{|c|}{ No. } & \multirow[b]{2}{*}{$O R^{a}$} & \multirow[b]{2}{*}{$95 \% \mathrm{Cl}$} & \multicolumn{2}{|c|}{ No. } & \multirow[b]{2}{*}{$O R^{\mathrm{a}}$} & \multirow[b]{2}{*}{$95 \% \mathrm{Cl}$} & \multicolumn{2}{|c|}{ No. } & \multirow[b]{2}{*}{$O R^{a}$} & \multirow[b]{2}{*}{$95 \% \mathrm{Cl}$} \\
\hline & Case & Control & & & Case & Control & & & Case & Control & & & Case & Control & & \\
\hline \multicolumn{17}{|l|}{$C Y P 1 A 1 * 2 A$} \\
\hline TT & 461 & 457 & 1.00 & & 175 & 168 & 1.00 & & 31 & 37 & 1.00 & & 255 & 252 & 1.00 & \\
\hline TC & 328 & 343 & 0.96 & $(0.78-1.19)$ & 173 & 187 & 1.01 & $(0.73-1.40)$ & 40 & 36 & 1.37 & $(0.64-2.90)$ & 115 & 120 & 0.95 & $(0.69-1.31)$ \\
\hline CC & 84 & 73 & 1.13 & $(0.79-1.61)$ & 55 & 48 & 1.09 & $(0.66-1.78)$ & 10 & 8 & 1.95 & $(0.63-6.06)$ & 19 & 17 & 1.06 & $(0.54-2.09)$ \\
\hline $\mathrm{CC}+\mathrm{TC}$ & 412 & 416 & 0.99 & $(0.81-1.21)$ & 228 & 235 & 1.02 & $(0.75-1.40)$ & 50 & 44 & 1.49 & $(0.74-2.99)$ & 134 & 137 & 0.97 & $(0.71-1.31)$ \\
\hline \multicolumn{17}{|l|}{$C Y P 1 A 1 * 2 C$} \\
\hline Ile/lle & 592 & 613 & 1.00 & & 246 & 249 & 1.00 & & 46 & 50 & 1.00 & & 300 & 314 & 1.00 & \\
\hline Ile/Val & 245 & 232 & 1.10 & $(0.88-1.38)$ & 137 & 134 & 1.10 & $(0.80-1.52)$ & 30 & 28 & 1.40 & $(0.66-2.94)$ & 78 & 70 & 1.13 & $(0.77-1.65)$ \\
\hline $\mathrm{Val} / \mathrm{Nal}$ & 29 & 28 & 1.08 & $(0.63-1.85)$ & 20 & 20 & 0.88 & $(0.44-1.77)$ & 0 & 3 & - & - & 9 & 5 & 2.02 & $(0.66-6.24)$ \\
\hline Ile/Val+Val/Val & 274 & 260 & 1.10 & (0.88-1.37) & 157 & 154 & 1.07 & $(0.79-1.46)$ & 30 & 31 & 1.27 & $(0.62-2.60)$ & 87 & 75 & 1.19 & $(0.83-1.71)$ \\
\hline \multicolumn{17}{|l|}{ CYP1A2*1F } \\
\hline AA & 362 & 370 & 1.00 & & 151 & 163 & 1.00 & & 30 & 32 & 1.00 & & 181 & 175 & 1.00 & \\
\hline$A C$ & 414 & 383 & 1.12 & $(0.90-1.37)$ & 202 & 186 & 1.21 & (0.88-1.68) & 33 & 37 & 0.96 & (0.47-1.93) & 179 & 160 & 1.09 & (0.79-1.49) \\
\hline CC & 96 & 120 & 0.84 & $(0.61-1.15)$ & 50 & 54 & 1.04 & $(0.66-1.64)$ & 17 & 12 & 1.70 & $(0.55-5.24)$ & 29 & 54 & 0.54 & $(0.32-0.90)$ \\
\hline $\mathrm{CC}+\mathrm{AC}$ & 510 & 503 & 1.05 & $(0.86-1.28)$ & 252 & 240 & 1.17 & $(0.86-1.58)$ & 50 & 49 & 1.09 & (0.57-2.09) & 208 & 214 & 0.96 & (0.71-1.29) \\
\hline \multicolumn{17}{|l|}{ CYP1B1 $\mathrm{Arg}^{48}$ Gly } \\
\hline Arg/Arg & 536 & 553 & 1.00 & & 307 & 316 & 1.00 & & 61 & 67 & 1.00 & & 168 & 170 & 1.00 & \\
\hline Arg/Gly & 275 & 264 & 1.09 & (0.87-1.35) & 92 & 79 & 1.26 & $(0.88-1.83)$ & 17 & 12 & 1.49 & $(0.65-3.42)$ & 166 & 173 & 0.93 & $(0.67-1.26)$ \\
\hline Gly/Gly & 61 & 56 & 1.31 & $(0.85-2.00)$ & 4 & 8 & 0.48 & $(0.13-1.75)$ & 3 & 2 & 1.66 & $(0.26-10.75)$ & 54 & 46 & 1.30 & $(0.81-2.10)$ \\
\hline Arg/Gly+Gly/Gly & 336 & 320 & 1.12 & (0.90-1.38) & 96 & 87 & 1.19 & (0.83-1.69) & 20 & 14 & 1.51 & $(0.69-3.31)$ & 220 & 219 & 1.00 & $(0.75-1.33)$ \\
\hline \multicolumn{17}{|l|}{ CYP1B1 Leu+432 Val } \\
\hline Leu/Leu & 505 & 479 & 1.00 & & 310 & 285 & 1.00 & & 67 & 58 & 1.00 & & 128 & 136 & 1.00 & \\
\hline Leu/Val & 281 & 297 & 0.84 & (0.67-1.05) & 83 & 111 & 0.65 & $(0.45-0.94)$ & 12 & 20 & 0.58 & $(0.24-1.40)$ & 186 & 166 & 1.10 & $(0.80-1.52)$ \\
\hline $\mathrm{Val} / \mathrm{Val}$ & 87 & 97 & 0.82 & (0.56-1.19) & 10 & 7 & 1.18 & $(0.36-3.83)$ & 2 & 3 & 0.54 & (0.07-4.16) & 75 & 87 & 0.87 & (0.57-1.32) \\
\hline Leu/Val+Val/Val & 368 & 394 & 0.84 & $(0.67-1.03)$ & 93 & 118 & 0.68 & $(0.48-0.97)$ & 14 & 23 & 0.57 & $(0.25-1.30)$ & 261 & 253 & 1.03 & $(0.76-1.40)$ \\
\hline \multicolumn{17}{|l|}{ СУР $3 A 5 * 3$} \\
\hline *3/*3 & 491 & 506 & 1.00 & & 210 & 251 & 1.00 & & 44 & 42 & 1.00 & & 237 & 213 & 1.00 & \\
\hline$* 3 /{ }^{*} 1$ & 309 & 304 & 1.05 & $(0.85-1.31)$ & 160 & 132 & 1.43 & (1.04-1.99) & 34 & 30 & 1.23 & $(0.60-2.53)$ & 115 & 142 & 0.72 & $(0.51-1.01)$ \\
\hline${ }^{*} 1 /{ }^{*} 1$ & 73 & 63 & 1.12 & $(0.77-1.65)$ & 33 & 20 & 1.91 & $(0.97-3.76)$ & 3 & 9 & 0.10 & $(0.02-0.66)$ & 37 & 34 & 0.92 & $(0.54-1.56)$ \\
\hline${ }^{*} 3 /{ }^{*} 1+{ }^{*} 1 /{ }^{*} 1$ & 382 & 367 & 1.07 & $(0.87-1.31)$ & 193 & 152 & 1.49 & $(1.10-2.04)$ & 37 & 39 & 0.88 & $(0.46-1.68)$ & 152 & 176 & 0.76 & $(0.55-1.04)$ \\
\hline $\begin{array}{l}\text { Abbreviations: } \mathrm{Cl} \text {, cor } \\
\text { a'onditional model ac } \\
\text { ORs and } 95 \% \text { Cls wit }\end{array}$ & tatistica & $\begin{array}{l}\text { 1; JB, Japai } \\
\text { opausal sta } \\
\text { nificance a }\end{array}$ & ritten in & $\begin{array}{l}\text { living in São Pau } \\
\text { opause, number } \\
\text { d letters. }\end{array}$ & 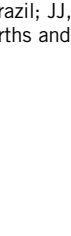 & $\begin{array}{l}\text { se livit } \\
\text { g statu }\end{array}$ & & & & & & OR, odds ratio. & & & & \\
\hline
\end{tabular}


frequencies among the individual populations (Table 3) were reasonably similar to those previously reported in that population (Table 1).

In contrast, a limitation of this study is that the stratified analyses involved a relatively small number of cases, meaning that the interpretability of our results might be limited.

In conclusion, we found no overall association between any SNP examined and breast cancer risk in the three populations combined. In contrast, subgroup analyses demonstrated significant associations with a risk of $C Y P 1 A 2^{*} 1 F$ in $\mathrm{NJB}$, and $C Y P 1 B 1 \mathrm{Leu}^{432} \mathrm{Val}$ and $C Y P 3 A 5^{*} 3$ in JJ. Our findings add further evidence to the idea that genetic polymorphisms related to estrogen metabolism may play a role in the development of breast cancer.

\section{ACKNOWLEDGEMENTS}

This study was supported by a grant-in-aid for Research on Risk of Chemical Substances from the Ministry of Health, Labour and Welfare of Japan and grants-in-aid for Scientific Research on Priority Areas (17015049) and for young scientists (B) (17790378 and 19790415) from the Ministry of Education, Culture, Sports, Science and Technology of Japan and the Japan Society for the Promotion of Science. We are grateful to the participants in the 'São PauloJapan Breast Cancer Study Group': T Hanaoka, M Kobayashi, J Ishihara, S Ikeda and C Nishimoto (Research Center for Cancer Prevention and Screening, National Cancer Center, Tokyo); CI Yamaguchi, CM Kunieda and SS Sugama (Nikkei Disease Prevention Center, São Paulo); CK Taniguchi and JA Marques (Departamento de Ginecologia, Hospital Pérola Byington, São Paulo); MR Eichhorn (Departamento de Nutrição, Hospital Pérola Byington, São Paulo); H Iyeyasu, MS Maciel, SMT Carvalho, JBD Collins and CEM Fontes (Departamento de Mastologia, Hospital AC Camargo, São Paulo); LP Kowalski and JMF Toyota (Departamento de Cirurgia de Cabeça e Pescoço e Otorrinolaringologia, AC Camargo Hospital, São Paulo); EM Barbosa (Departamento de Mastologia, Instituto Brasileiro de Controle ao Câncer, São Paulo); O Ferraro (Departamento de Mastologia, Hospital do Servidor Público Estadual Francisco Morato de Oliveira, São Paulo); R Anzai (Departamento de Mastologia, Hospital Santa Cruz); EH Hotta and DA Petti (Instituto de Ginecologia e Mastologia, Hospital Beneficencia Portuguesa); S Mendes (Instituto Brasileiro de Mastologia e Ginecologia, Hospital Beneficencia Portuguesa). We also thank Dr Reiko Kishi and Dr Fumihiro Sata of Department of Public Health, Hokkaido University Graduate School of Medicine, Sapporo, Japan for their helpful comments.

1 Toniolo, P. G., Levitz, M., Zeleniuch Jacquotte, A., Banerjee, S., Koenig, K. L., Shore, R. E. et al. A prospective study of endogenous estrogens and breast cancer in postmenopausal women. J. Natl Cancer Inst. 87, 190-197 (1995).

2 Mitrunen, K., Hirvonen, A. Molecular epidemiology of sporadic breast cancer. The role of polymorphic genes involved in oestrogen biosynthesis and metabolism. Mutat. Res. 544, 9-41 (2003)

3 Zhu, B. T., Conney, A. H. Functional role of estrogen metabolism in target cells: review and perspectives. Carcinogenesis 19, 1-27 (1998).

4 Kabat, G. C., Chang, C. J., Sparano, J. A., Sepkovie, D. W., Hu, X. P., Khalil, A. et al. Urinary estrogen metabolites and breast cancer: a case-control study. Cancer Epidemiol. Biomarkers. Prev. 6, 505-509 (1997).

5 Fowke, J. H., Qi, D., Bradlow, H. L., Shu, X. O., Gao, Y. T., Cheng, J. R. et al. Urinary estrogen metabolites and breast cancer: differential pattern of risk found with preversus post-treatment collection. Steroids 68, 65-72 (2003).

6 Adlercreutz, H., Gorbach, S. L., Goldin, B. R., Woods, M. N., Dwyer, J. T., Hamalainen, E. Estrogen metabolism and excretion in Oriental and Caucasian women. J. Nat/ Cancer Inst. 86, 1076-1082 (1994).

7 Meilahn, E. N., De Stavola, B., Allen, D. S., Fentiman, I., Bradlow, H. L., Sepkovic, D. W. et al. Do urinary oestrogen metabolites predict breast cancer? Guernsey III cohort follow-up. Br. J. Cancer 78, 1250-1255 (1998).

8 Eliassen, A. H., Missmer, S. A., Tworoger, S. S., Hankinson, S. E. Circulating 2-hydroxyand 16alpha-hydroxy estrone levels and risk of breast cancer among postmenopausal women. Cancer Epidemiol. Biomarkers Prev. 17, 2029-2035 (2008).

9 Huang, Z., Fasco, M. J., Figge, H. L., Keyomarsi, K., Kaminsky, L. S. Expression of cytochromes P450 in human breast tissue and tumors. Drug Metab. Dispos. 24, 899-905 (1996).
10 Cribb, A. E., Knight, M. J., Dryer, D., Guernsey, J., Hender, K., Tesch, M. et al. Role of polymorphic human cytochrome P450 enzymes in estrone oxidation. Cancer Epidemiol. Biomarkers Prev. 15, 551-558 (2006).

11 Sachse, C., Brockmoller, J., Bauer, S., Roots, I. Functional significance of a $C \rightarrow A$ polymorphism in intron 1 of the cytochrome P450 CYP1A2 gene tested with caffeine. Br. J. Clin. Pharmacol. 47, 445-449 (1999).

12 Kuehl, P., Zhang, J., Lin, Y., Lamba, J., Assem, M., Schuetz, J. et al. Sequence diversity in CYP3A promoters and characterization of the genetic basis of polymorphic CYP3A5 expression. Nat. Genet. 27, 383-391 (2001).

13 Miyoshi, Y., Noguchi, S. Polymorphisms of estrogen synthesizing and metabolizing genes and breast cancer risk in Japanese women. Biomed. Pharmacother. 57, 471-481 (2003).

14 Le Marchand, L., Donlon, T., Kolonel, L. N., Henderson, B. E., Wilkens, L. R. Estrogen metabolism-related genes and breast cancer risk: the multiethnic cohort study. Cancer Epidemiol. Biomarkers Prev. 14, 1998-2003 (2005).

15 Chen, C., Huang, Y., Li, Y., Mao, Y., Xie, Y. Cytochrome P450 1A1 (CYP1A1) T3801C and $\mathrm{A} 2455 \mathrm{G}$ polymorphisms in breast cancer risk: a meta-analysis. J. Hum. Genet. 52, 423-435 (2007).

16 Paracchini, V., Pedotti, P., Raimondi, S., Garte, S., Bradlow, H. L., Sepkovic, D. W. et al. A common CYP1B1 polymorphism is associated with 2-OHE1/16-OHE1 urinary estrone ratio. Clin. Chem. Lab. Med. 43, 702-706 (2005).

17 Lurie, G., Maskarinec, G., Kaaks, R., Stanczyk, F. Z., Le Marchand, L. Association of genetic polymorphisms with serum estrogens measured multiple times during a 2-year period in premenopausal women. Cancer Epidemiol. Biomarkers Prev. 14, 1521-1527 (2005).

18 Yoshimura, K., Hanaoka, T., Ohnami, S., Ohnami, S., Kohno, T., Liu, Y. et al. Allele frequencies of single nucleotide polymorphisms (SNPs) in 40 candidate genes for gene-environment studies on cancer: data from population-based Japanese random samples. J. Hum. Gene. 48, 654-658 (2003).

19 Dunning, A. M., Dowsett, M., Healey, C. S., Tee, L., Luben, R. N., Folkerd, E. et al. Polymorphisms associated with circulating sex hormone levels in postmenopausal women. J. Natl Cancer Inst. 96, 936-945 (2004).

20 Fukuen, S., Fukuda, T., Maune, H., Ikenaga, Y., Yamamoto, I., Inaba, T. et al. Novel detection assay by PCR-RFLP and frequency of the CYP3A5 SNPs, CYP3A5*3 and *6, in a Japanese population. Pharmacogenetics 12, 331-334 (2002).

21 Hiratsuka, M., Takekuma, Y., Endo, N., Narahara, K., Hamdy, S. I., Kishikawa, Y. et al. Allele and genotype frequencies of CYP2B6 and CYP3A5 in the Japanese population. Eur. J. Clin. Pharmacol. 58, 417-421 (2002).

22 Saeki, M., Saito, Y., Nakamura, T., Murayama, N., Kim, S. R., Ozawa, S. et al. Single nucleotide polymorphisms and haplotype frequencies of CYP3A5 in a Japanese population. Hum. Mutat. 21, 653 (2003).

23 Plummer, S. J., Conti, D. V., Paris, P. L., Curran, A. P., Casey, G., Witte, J. S. CYP3A4 and CYP3A5 genotypes, haplotypes, and risk of prostate cancer. Cancer Epidemiol. Biomarkers Prev. 12s, 928-932 (2003).

24 Paracchini, V., Raimondi, S., Gram, I. T., Kang, D., Kocabas, N. A., Kristensen, V. N. et al. Meta- and pooled analyses of the cytochrome P-450 1B1 Val432Leu polymorphism and breast cancer: a HuGE-GSEC review. Am. J. Epidemiol. 165, 115-125 (2007)

25 Miyoshi, Y., Takahashi, Y., Egawa, C., Noguchi, S. Breast cancer risk associated with CYP1A1 genetic polymorphisms in Japanese women. Breast J. 8, 209-215 (2002).

26 Iwasaki, M., Hamada, G. S., Nishimoto, I. N., Netto, M. M., Motola, J. Jr, Laginha, F. M. et al. Dietary isoflavone intake and breast cancer risk in case-control studies in Japanese, Japanese Brazilians, and non-Japanese Brazilians. Breast Cancer Res. Treat. 2008. Sep., 6 (2008).

27 Shen, Y., Li, D. K., Wu, J., Zhang, Z., Gao, E. Joint effects of the CYP1A1 Mspl, ERalpha Pvull, and ERalpha Xbal polymorphisms on the risk of breast cancer: results from a population-based case-control study in Shanghai, China. Cancer Epidemiol. Biomarkers Prev. 15, 342-347 (2006)

28 Han, W., Kang, D., Park, I. A., Kim, S. W., Bae, J. Y., Chung, K. W. et al. Associations between breast cancer susceptibility gene polymorphisms and clinicopathological features. Clin. Cancer Res. 10, 124-130 (2004).

29 Modugno, F., Zmuda, J. M., Potter, D., Cai, C., Ziv, E., Cummings, S. R. et al. Estrogen metabolizing polymorphisms and breast cancer risk among older white women. Breast Cancer Res. Treat. 93, 261-270 (2005).

30 Long, J. R., Egan, K. M., Dunning, L., Shu, X. O., Cai, Q., Cai, H. et al. Population-based case-control study of AhR (aryl hydrocarbon receptor) and CYP1A2 polymorphisms and breast cancer risk. Pharmacogenet. Genomics 16, 237-243 (2006).

31 Rebbeck, T. R., Troxel, A. B., Walker, A. H., Panossian, S., Gallagher, S., Shatalova, E. G. et al. Pairwise combinations of estrogen metabolism genotypes in postmenopausal breast cancer etiology. Cancer Epidemiol. Biomarkers Prev. 16, 444-450 (2007).

32 Kotsopoulos, J., Ghadirian, P., El Sohemy, A., Lynch, H. T., Snyder, C., Daly, M. et al. The CYP1A2 genotype modifies the association between coffee consumption and breast cancer risk among BRCA1 mutation carriers. Cancer Epidemiol. Biomarkers Prev. 16, 912-916 (2007).

33 Gulyaeva, L. F., Mikhailova, O. N., Pustylnyak, V. O., Kim, I. V. IV, Gerasimov, A. V., Krasilnikov, S. E. et al. Comparative analysis of SNP in estrogen-metabolizing enzymes for ovarian, endometrial, and breast cancers in Novosibirsk, Russia. Adv. Exp. Med. Biol. 617, 359-366 (2008) 
34 Shimada, T., Watanabe, J., Kawajiri, K., Sutter, T. R., Guengerich, F. P., Gillam, E. M. et al. Catalytic properties of polymorphic human cytochrome P450 1B1 variants. Carcinogenesis 20, 1607-1613 (1999).

35 Gallicchio, L., Berndt, S. I., McSorley, M. A., Newschaffer, C. J., Thuita, L. W., Argani, P. et al. Polymorphisms in estrogen-metabolizing and estrogen receptor genes and the risk of developing breast cancer among a cohort of women with benign breast disease. BMC Cancer 6, 173 (2006).

36 Gaudet, M. M., Chanock, S., Lissowska, J., Berndt, S. I., Yang, X. R., Peplonska, B. et al. Genetic variation of Cytochrome P450 1B1 (CYP1B1) and risk of breast cancer among Polish women. Pharmacogenet. Genomics 16, 547-553 (2006).

37 Shou, M., Korzekwa, K. R., Brooks, E. N., Krausz, K. W., Gonzalez, F. J., Gelboin, H. V. Role of human hepatic cytochrome P450 1A2 and 3A4 in the metabolic activation of estrone. Carcinogenesis 18, 207-214 (1997).
38 Huang, Z., Guengerich, F. P., Kaminsky, L. S. 16Alpha-hydroxylation of estrone by human cytochrome P450 3A4/5. Carcinogenesis 19, 867-872 (1998).

39 Lee, A. J., Conney, A. H., Zhu, B. T. Human cytochrome P450 3A7 has a distinct high catalytic activity for the 16 alpha-hydroxylation of estrone but not 17 beta-estradiol. Cancer Res. 63, 6532-6536 (2003).

40 Shen, D. D., Kunze, K. L., Thummel, K. E. Enzyme-catalyzed processes of first-pass hepatic and intestinal drug extraction. Adv. Drug. Deliv. Rev. 27, 99-127 (1997).

41 Lamba, J. K., Lin, Y. S., Schuetz, E. G., Thummel, K. E. Genetic contribution to variable human CYP3A-mediated metabolism. Adv. Drug. Deliv. Rev. 54, 1271-1294 (2002).

42 Vaarala, M. H., Mattila, H., Ohtonen, P., Tammela, T. L., Paavonen, T. K., Schleutker, J. The interaction of CYP3A5 polymorphisms along the androgen metabolism pathway in prostate cancer. Int. J. Cancer 122, 2511-2516 (2008). 